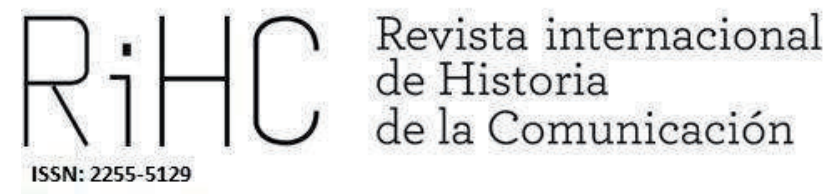

\title{
GENEALOGÍAS FEMINISTAS IBÉRICAS: ITINERARIOS DESDE LA COMUNICACIÓN Y EL ACTIVISMO EN TORNO A SORORIDADES COMPARTIDAS
}

Iberian feminist genealogies: itineraries from communication and activism around shared sisterhoods

DOI: http://dx.doi.org/10.12795/RiCH.2021.i16.03

Recibido: 23-4-2021

Aceptado: $12-6-2021$

Publicado: 30-5-2021

Ma Teresa Vera Balanza

Universidad de Málaga, España

teresavera@uma.es

ORCID (D) https://orcid.org/0000-0002-3089-4469

Rosa María Ballesteros García

Universidad de Málaga, España

rosaballesterosgarcia@gmail.com

ORCID (D) https://orcid.org/0000-0002-7462-4831

Como citar este artículo:

VERA BALANZA, M Teresa y BALLESTEROS GARCÍA, Rosa María (2021): “Genealogías feministas ibéricas: itinerarios desde la comunicación y el activismo en torno a sororidades compartidas", en Revista Internacional de Historia de la Comunicación, no16, 2021, pp. 42-64 http://dx.doi.org/10.12795/RiCH.2021.i16.03 
Resumen: La sororidad se refiere a la hermandad entre mujeres a la hora de plantearnos cuestiones sociales que nos atañen como grupo. Desde esta aportación nos proponemos implementar la línea del iberismo tanto en la creación de redes de colaboración en la actividad política como en el desempeño profesional del periodismo como modalidades complementarias del ejercicio de la ciudadanía. Así el movimiento de mujeres que a los dos lados de la frontera se va configurando durante los siglos XIX y XX confluye con el acceso a una profesión que permite, a la vez, denunciar las inequidades y difundir la educación de las mujeres como mecanismo para solventar la situación de injusticia social. Esta sororidad fue consolidándose pero también fracturándose o posponiendo en función de las dinámicas políticas. Las trayectorias personales y profesionales de nuestras antecesoras presentan unas similitudes y nutren una genealogía propia. Describiremos dos itinerarios: uno, el que parte de las experiencias activistas de las lusas Adelaide Cabete y Carolina B. Ângelo y la española Carmen de Burgos (Colombine); otro, el que aglutina a varias de las profesionales hispanas y las lusas, especialmente Ana de Castro y Carmen de Burgos, que nutren a toda una generación de periodistas, reporteras, cronistas, que son modelos y referentes de las comunicadoras de hoy.

Palabras clave: feminismo, genealogía, periodistas, Portugal, España.

\begin{abstract}
Sorority refers to the sisterhood between women when it comes to raising social issues that concern us as a group. From this contribution we propose to implement the Iberalism line both in the creation of collaborative networks in political activity and in the professional performance of journalism as complementary modalities of the exercise of citizenship. Thus, the women's movement that took shape on both sides of the border during the 19th and 20th centuries converged with access to a profession that made it possible both to denounce inequalities and to disseminate women's education as a mechanism for resolving the situation of social injustice. This sorority was consolidated but also fractured or postponed depending on the political dynamics, the personal and professional trajectories of our predecessors have some similarities and nourish a whole genealogy. We will describe two itineraries: one, which starts with the activist experiences of the Portuguese Adelaide Cabete and Carolina B. ngelo and the Spanish Carmen de Burgos (Colombine); the other, which brings together several of the Hispanic and Portuguese professionals, especially Ana de Castro and Carmen de Burgos, who nurtured a whole generation of journalists, reporters, chroniclers, who are models and references for today's women communicators.
\end{abstract}

Keywords: Feminism, Genealogy, Journalism, Portugal, Spain.

\title{
Introducción
}

Como cualquier otro portugués antiguo o moderno, fui instruido en la firme convicción de que mi enemigo natural es, y siempre había de serlo, España.

José Saramago, en Prólogo a Molina (1990) Sobre el Iberismo y otros escritos de literatura portuguesa 
La sororidad se refiere a la hermandad entre mujeres a la hora de plantearnos cuestiones sociales que nos atañen como grupo. Desde esta aportación nos proponemos implementar la línea del iberismo en la creación de redes de colaboración, en la actividad política como en el desempeño profesional del periodismo como modalidades complementarias del ejercicio de la ciudadanía. Así, el movimiento de mujeres que a los dos lados de la frontera se va configurando durante los siglos XIX y XX confluye con el acceso a una profesión que permite, a la vez, denunciar las inequidades y difundir la educación de las mujeres como mecanismo para solventar la situación de injusticia social. Esta sororidad fue consolidándose pero también fracturándose o posponiendo en función de las dinámicas políticas, las trayectorias personales y profesionales de nuestras antecesoras que presentan ciertas similitudes y nutren una genealogía propia. Nuestra propuesta describe varios itinerarios: uno, el que parte de las experiencias de las activistas lusas Adelaide Cabete y Carolina B. Ângelo y la española Carmen de Burgos (Colombine), las tres coetáneas, las tres masonas, comprometidas y vinculadas por esos lazos que tejen un movimiento feminista de raíz ibérica; otro, el que aglutina a varias de las profesionales hispanas y las lusas, especialmente a Ana de Castro y a Carmen de Burgos, que nutren a toda una generación de periodistas, reporteras, cronistas, que son modelos y referentes de las comunicadoras de hoy.

Junto a las coincidencias, a ambos lados de la frontera persisten las disidencias derivadas de las distintas culturas políticas. Por la reivindicación del sufragio femenino o el anticlericalismo, entre otras causas, como expresa nítidamente la dirigente lusa María Veleda (1871-1955) fundadora de las revistas A Asa, O Futuro, A Vanguarda Espiritista: «É impossível compatibilizar a Liberdade com a Crença. Uma há-de, fatalmente, esmagar a outra» (Monteiro, 2004: 86). Debido al radicalismo y a su heterodoxia, Veleda fue excluida de la dirección de la Liga Republicana de Mulheres Portuguesas (LRMP), creada por ella misma en 1908 junto con Cabete, Castro y Ângelo, por considerarla «demasiado vermelha», al estimar que sería contraproducente para la mayoría de socias, mucho más conservadoras.

Por otro lado, en el caso portugués, la proclamación de la República en 1910 fue el contexto político que propició la eclosión del movimiento feminista en aquel país, ahogado, como se sabe, con la implantación de la dictadura salazarista. En España, por su parte, esa eclosión maduraría a lo largo de la década de los años 20, durante los años de la Dictadura de Primo de Rivera, para continuar en la década siguiente con la proclamación de la Segunda República en 1931 y la obtención del voto femenino. El triste epílogo de la Guerra Civil española (1936-1939) sumirá de nuevo a las mujeres en el estado dependiente y subsidiario, despojándolas, tras la victoria franquista y durante la larga dictadura, de todos los derechos adquiridos.

También las lusas Cabete, Castro y Ângelo militaron en la Liga Feminina Portuguesa da Paz, fundada en 1899 en una filiación pacifista y antimilitarista que teníaen España como 
figuras relevantes a las hermanas Carvia Bernal, Rosario de Acuña o Belén Sárraga, todas ellas ligadas al republicanismo y al librepensamiento (Ramos, 2002). También en el caso español se detectan diferencias entre las feministas agrupadas en organizaciones como la ANME (1918) o el Lyceum Club Femenino (1926), especialmente por el derecho al voto, cuestión que tuvo su punto álgido durante el debate entre Clara Campoamor y Victoria Kent en las Cortes Constituyentes de 1931. El Lyceum, especialmente, fue un punto de encuentro muy importante para las discusiones sobre el sufragio femenino, a la par que un espacio en el que se desarrollaría esa sororidad que apuntamos en el título de nuestro artículo. En definitiva, las trayectorias similares tienen también elementos diferenciales que no pueden interpretarse como debilidades sino como consecuencias de la confluencia de proyectos políticos diferentes con trayectorias particulares que incorporan la causa de las mujeres con un encaje a veces dificultoso.

Partiendo de las experiencias de las activistas coetáneas, comprometidas y vinculadas por esos lazos aludidos, iniciaremos nuestros itinerarios e intentaremos dar visibilidad a las luces y las sombras que, a nuestro juicio, conformaron la personalidad y también la solidaridad del movimiento feminista de raíz ibérica, especialmente asentado en la vindicación del derecho a la educación y las escuelas de maestras, verdadero vivero del feminismo (Flecha, 2019). En el caso español, la educación universal verdadera clave de bóveda del movimiento de mujeres, también era una prioridad (Flecha, 1996) con ejemplos como la Liga de Educación y Enseñanza (LEYE), dirigida por Ana María Ronda Pérez y Matilde Muñoz. Masonas, maestras y feministas, la propia Ana de Castro afirma que en la logia portuguesa "Carolina Beatriz Ângelo», encontramos 32 «Hermanas», de las que 16 son maestras (Marques, s.a.: 56). La misma fuente, a la altura de 1926 afirma que la Logia Mixta "Humanidade do Direito Humano» acoge también un buen número de enseñantes, entre otras Domingas Lazary Amaral («Heloisa d’Adelard»), Maria José Ramos («Joana D’Arc») o Maria da Luz Pereira («Charlott Corday») (Marques, s.a.: 66).

Por otra parte, en las últimas décadas del siglo XIX se abren otras expectativas para futuras universitarias en disciplinas tan masculinizadas como la medicina, de la que forman parte dos de nuestras biografiadas. Surgen así los primeros nombres de futuras doctoras como las catalanas Dolores Aleu (1857-1913), Elena Maseras (1853-1905), Concepción Aleixandre (1862-1952) o Milagros Andreu (1880-1945); en el caso portugués son Elisa Augusta da Conceição Andrade, licenciada en 1884, Amélia Cardia dos Santos Costa (1855-1938), Aurélia de Morais Sarmento (1869-[?]), Laurinda de Morais Sarmento (1867-[?]), todas licenciadas en 1891. Nuestras biografiadas Adelaide Cabete y Carolina Ângelo se licenciaron en 1901 y 1903, respectivamente, y todas ellas se especializaron en ramas relacionadas con las mujeres y la infancia: ginecología, obstetricia o pediatría; de hecho Ângelo se licencia con una Tesis sobre Prolapsos Genitais (Sameiro Barroso, 2017). Eran conscientes de la importancia del conocimiento sobre el cuerpo propio, de lo que podían hacer por el resto de las mujeres y, también, 
de la acción de reivindicar la autoridad científica-médica sobre el cuerpo social de las mujeres.

Las formas de la sororidad practicada entre buena parte de las feministas lusitanas y españolas se concretan en las relaciones personales. Igualmente en la propia institucionalización mediante las organizaciones paralelas de mujeres $y$, específicamente, en la Unión Ibérica de escritoras (Ezama, 2010). E incluso también, con un sentido comunicativo e intencional, con referencias mutuas en los medios escritos en los que colaboraban con un sentido consciente de trascender a la opinión pública como agentes y como colectivo. Pardo Bazán establece relaciones literarias antes que personales y publica un largo artículo en el Almanach das Senhoras titulado, irónicamente, "Vecinos que no se tratan" (1884). Adelaide Cabete fue entrevistada por Clara Campoamor (1888-1972) para el periódico madrileño La Libertad (13/9/1928). Ese mismo año la doctora Elisa Soriano Fischer (1891-1964), presidenta de la Juventud Universitaria Feminista de España visitaba Lisboa y años antes, en 1911, recién proclamada la Primera República portuguesa, la dramaturga y feminista española Rosario de Acuña (1850-1923) se exiliaba en el país vecino huyendo de los rigores de los reaccionarios. La activista federalista Belén Sárraga (1874-1951), en gira política por aquel país, fue entrevistada por Ana de Castro para Almanach das Senhoras; en Lisboa "estuvo descansando" en una casita de Campo Grande, tras una larga gira propagandista por varios países de Iberoamérica, y fruto de aquella experiencia, publicaría en 1914 El clericalismo en América. La escritora y pedagoga Alice Pestana (1860-1929), fundadora en 1899 de la Liga Portuguesa da Paz, casada con el profesor Pedro Blanco Suárez (1869-1950), vivió en Madrid desde 1901, y desarrollaron ambos su docencia en la Institución Libre de Enseñanza. En 1914 realizó, pensionada por el Gobierno español, un informe sobre los avances logrados por la Primera República portuguesa en materia de educación en todos los órdenes. Si a todo ello se une la fructífera relación entre Carmen de Burgos y Ana de Castro, se evidencia que la porosidad de la frontera fue real y no solo política; sirvió como vía de escape en los momentos de reacción pero también como territorio de encuentro, de reconocimiento y de interés mutuo.

Han sido esencialmente Concepción Núñez $(2005,2014)$ a través de sus indagaciones sobre Carmen de Burgos, y Ángeles Ezama Gil, $(2010,2013,2014)$ a partir de las coetáneas, quienes han nutrido esta línea de investigación que tiene su referente paralelo en las aportaciones de Lousada (2010, 2012, 2014, 2017). Contamos las exploraciones sobre las relaciones entre las periodistas en Portugal y Brasil de Coutinho y Da Cruz (2018) y las reporteras de la segunda mitad del siglo XX (Ventura, 2012); también con una genealogía sobre escritoras lesbianas (Fariña Busto, 2019) en Portugal y España. En definitiva, la fortaleza y la fecundidad de estas indagaciones avalan la necesidad de implementar estas línea de manera individual, pero también de seguir explorando las relaciones entre países, así como incidir en el estudio de los "lugares 
propios" en que se desarrolló esa sororidad entre las feministas hispano-lusas, como el ya citado Lyceum Club, la AMNE o la Unión Ibérica.

\section{Metodología}

Este estudio consiste en una investigación de corte analítico y de carácter histórico en el que partimos de la literatura precedente sobre los movimientos de mujeres en España y Portugal y sobre la difusión de las ideas igualitarias (Ballesteros, 1999 a; Da Silva, 1983; Guimaraes, 1986; Ramos, 2005) para recomponer unos itinerarios explicativos (Pérez Isasi y Rodrigues, 2021). Recurrimos a un análisis de los contenidos en textos de referencia y aportaciones en publicaciones sobre las autoras españolas y portuguesas en el tránsito del siglo XIX al XX para ubicarlas y recabar sus contribuciones en las publicaciones periódicas de la etapa analizada. A partir de estas colaboraciones hemos ido estableciendo inferencias relacionales entre ellas en un proceso de inducción lógica (Coutinho, 2014: 376).

Esta recopilación trata de reconstruir a partir de las historias literarias androcéntricas una genealogía (Restrepo: 2016) que recomponga el tratamiento hasta ahora individualizado y biográfico de los sujetos históricos, toda vez que en el caso de las mujeres esos abordajes constituyen excepcionalidades y rarezas que ni generan modelos ni poseen la suficiente entidad para convertirse en referentes de autoridad. Por ello, los estudios feministas se han propuesto no solo la tarea de desvelamiento sino la de construcción relacional del colectivo. En la medida en que se conoce esa situación no se niega la subordinación, pero sí que se redimensiona al no tratarse de experiencias unitarias sino de mecanismos premeditados de sometimiento colectivo, de dominación del patriarcado mediante un mecanismo de poder simbólico y paradigma oculto del saber (Rodríguez Magda, 2004). Analizarlas en su continuidad no anula la individualidad, antes al contrario, refuerza a los sujetos, nutre las genealogías y otorga tradición y autoridad.

Desde una perspectiva crítica, se propone superar la historia relato para optar por la historia problema, en una línea foucaultiana de hacer arqueología del saber/poder e inscribirse en un proyecto colectivo de transformación social (Álvarez, 2008:19), a partir de la recuperación de la intrahistoria de la gente que, aún participando de la Historia, no permanece en el recuerdo oficial de los pueblos (Unamuno, 1972). Desde el enfoque sociológico, se gestiona la voluntad de reunir, objetivar e instituir el sentido de lo colectivo entroncado con la propuesta de Bourdieu cuando enfatiza el rol del poder simbólico en la formación de grupos: «el poder simbólico, cuya forma por excelencia es el poder de hacer grupos y consagrarlos o instituirlos, consiste en el poder de hacer que algo existe en estado formal objetivado, público, lo que previamente sólo existía en 
estado implícito» (Bourdieu, 2000). Así, las contribuciones individuales de nuestras biografiadas y el sistema de redes que articulan a un lado y a otro de la frontera y más allá del Atlántico, posee el sentido de grupo; ignorarlo constituiría una práctica, por consiguiente, de violencia simbólica.

Como bien explica Rodríguez Magda (1997), es preceptivo diferenciar entre la genealogía femenina y la genealogía feminista. La femenina, estima la recuperación de prototipos literarios y mitológicos, las galerías de mujeres ilustres en la búsqueda de la construcción del imaginario, la simbología, la memoria y la presencia femeninas, incluyendo tanto a mujeres reales como ficticias, feministas o no. La genealogía feminista es memoria colectiva de las luchas por la emancipación, de las pioneras reales que hayan contribuido a los logros feministas con sus acciones e ideas, donde caben también las aportaciones masculinas. Con todo, en esta propuesta necesitamos transitar de unas a otras, de las femeninas a las feministas, porque aunque nuestras referentes se incardinan en la segunda opción, establecieron también redes estratégicas con otras mujeres y con organizaciones políticas situadas en el nivel institucional de la República portuguesa.

Armonizando una y otra dimensión, Alejandra Ciriza (2012: 614) entiende las genealogías feministas como la "recuperación de la historia de nuestras antepasadas, de reconocimiento de los lazos que nos ligan con ellas, a sabiendas de que tal recuperación se produce a partir de un interés político y cognoscitivo ligado a la necesidad de historizar nuestra presencia en las luchas del pasado [...] la recuperación conlleva una labor de paciente recolección de lo disperso, a sabiendas de la provisoriedad de las junturas y de la tensión inherente a la tarea misma".

\section{Resultados: a modo de Itinerarios}

Presentamos unos itinerarios que nos permiten trazar dos hilos principales. El primero, el de las voces de las activistas y el segundo, complementario, donde esas mismas mujeres y otras coetáneas se convierten en altavoces en el uso de la prensa como vía de profesionalización y como canal difusor de sus proyectos políticos.

\subsection{Las voces del feminismo ibérico}

Adelaide de Jesus Damas Brazão Cabete (1867-1935).

Nació el mismo año que Carmen de Burgos en la alentejana Alcáçovas. De origen humilde, trabajó en faenas del campo y en el servicio doméstico en Elvas, por lo que su 
primera formación fue autodidacta, en línea con el alto analfabetismo del país. A este futuro tan poco prometedor se enfrentaba cuando se cruzó en su vida un sargento del ejército: Manuel Fernández Cabete, un «apóstol de la instrucción», republicano y con ideas avanzadas. Se casaron en 1886. Tenía ella 19 años y fue el detonante que dio un vuelco a su vida. Como afirma Isabel Lousada (2010:23): «E o casamento, ao invés de se tornar no "fado" ou em "fardo", tornou-se precisamente fonte de crescimento e liberdade».

Coinciden las fuentes que debió ser un hombre extraordinario para la época, un adelantado a eso que ahora denominamos conciliación profesional y familiar. Él fue quien insistió para que su joven e inteligente esposa desarrollara sus extraordinarias dotes y también quien la lanzó al activismo político. Manuel no poseía fortuna personal, pero vendió unas tierras que tenía para que su mujer pudiera estudiar. El primer regalo a su futura esposa fue una gramática. Adelaide, en 1910, junto a Carolina Ângelo, confeccionaron «20 bandeiras verdes-rubras no prazo máximo de 48 horas» (Lousada, 2010:14) que se izarían en Lisboa al proclamarse la República.

Adelaide Cabete, como fue conocida, afirmaba ser laica, republicana y socialista, con un punto ácrata como evidencia la decisión de tomar el nombre simbólico de Luisa Michel, en recuerdo de la revolucionaria anarquista en la Comuna parisina de 1871 , cuando fue iniciada en la masonería. Los años que permaneció en la Orden fueron tormentosos, con varias entradas y salidas de la logia relacionadas con el paso a logia adoptiva; esto es, se había perdido el derecho de igualdad dentro de la logia mixta (mujeres y hombres) para pasar a la categoría de adopción bajo la dependencia de una logia masculina. Posteriormente, en 1923, dirigió la logia mixta internacional «El Derecho Humano» y propició la creación de otras logias como la «Fiat lux» y «Trindade Leitão».

Por encima de todo, entendió que el estudio era el medio para la formación y el desarrollo de la ciudadanía, especialmente para las mujeres de las clases humildes tan desprotegidas y tan atrasadas como ella misma había estado. Prueba de este interés firmaba el artículo: "Instrua-se a mulher», publicado en O Elvense en 1901. En esta misma línea se manifestaba otra de nuestras feministas, Carmen de Burgos, al afirmar que sería la escuela «la antorcha que iluminaría el camino de la regeneración de los pueblos». A los 22 años, Cabete finalizó los estudios primarios. Cinco años más tarde concluía la enseñanza media siendo la única alumna entre 119 alumnos. Con 32 años, en 1900, después de pasar por la Escola Médico-Cirúrgica de Lisboa, concluyó la carrera de medicina defendiendo la tesis: "Protección de mujeres pobres embarazadas como un medio para promover el desarrollo físico de las nuevas generaciones». Esta vez no fue la única alumna, junto con Maria do Carmo Joquim Lopes se titularon frente a 36 hombres. Vemos pues, que, en apenas una década, una joven casi analfabeta había conseguido algo extraordinario: dar un vuelco definitivo a su vida para convertirse en una profesional de prestigio, aunque sin desclasarse, porque ayudó en los estudios a un 
sobrino y a una hermana más joven «...y que de este modo no se generase en su familia un gran desnivel social» (Silva, 1997:10).

En 1916 murió su compañero de vida, y ella siguió en la lucha que había comenzado por los derechos de las mujeres que defendió a través de diversas publicaciones como Alma Feminina, Almanaque Democrático o Ciência, así como conferencias o congresos internacionales feministas, como el de Gand (1913), Roma (1923) o Washington (1925). En el ámbito nacional intervino en los Congresos Feministas e da Educação (1921 y 1928) y Abolicionistas (1926 y 1929) y también en numerosos eventos o asociaciones entre los que destacamos la Liga Republicana de Mulheres Portuguesas (1908), Conselho Nacional de Mulheres Portuguesas (1914), Cruzada de Mulheres Portuguesas (1917) o Ligas de Bondade (1917). (Ballesteros, 2001: 292-295; Lousada, 2010: 9-22).

Fue médica, profesora del Instituto Femenino de Odivelas -hasta que en 1911 pasó a denominarse Instituto Feminino de Educação e Trabalho- y profesora durante 17 años en la Universidad Popular dirigiendo un curso sobre Higiene y Puericultura. Gran humanista, luchó contra el alcoholismo y la proliferación de tabernas, la violencia contra los animales (incluidas las corridas de toros) o el uso de juguetes bélicos, entre otras cuestiones. Su consultorio como obstetra y ginecóloga se situó en la Baixa de Lisboa.

Poco después de enviudar se trasladó junto a su sobrino, el abogado Arnaldo Brazão a Luanda, capital de Angola (por entonces colonia portuguesa), donde prosiguió con su profesión y sus artículos en los que atacaba valientemente las condiciones higiénicas de los indígenas. Estas críticas tuvieron su efecto (negativo) que se concretó en un atentado contra Cabete, aunque nunca se esclareció la responsabilidad del culpable (Silva, 1997). Su estancia en Luanda se prolongó hasta 1934. En 1933 fue la primera y única mujer en votar en Luanda, gracias a la Constitución de la Metrópoli de 1933. En 1934, ya enferma, regresó a Lisboa coincidiendo con la prohibición del Gobierno del «Estado Novo» de las sociedades secretas y de los partidos políticos (Lousada, 2017). Murió en Lisboa al año siguiente, el mismo año que su amiga y compañera Ana de Castro.

Carolina Beatriz Ângelo (1878-1911) nació en Guarda, ciudad de la Beira Alta, cerca de la frontera con España. A los 25 años, en 1903, se licenció en Medicina por la Universidad de Lisboa siendo la primera mujer en practicar la cirugía en Portugal. El mismo año de su licenciatura contrajo matrimonio con su primo y colega Januário Gonçalves Barreto, médico y activista republicano y también deportista (llegó a presidir la Liga de Fútbol del país) y dirigió también la Academia Lisbonense y la Sociedad Promotora de Educación Física. Murió muy joven, a los 33 años, en 1910, dejándola viuda y con una hija. Carolina apenas le sobrevivió, pues murió al año siguiente, también con 33 años, víctima de un infarto cuando salía de una reunión de la Liga Feminista, de la que era socia y cofundadora. El periódico lisboeta O Mundo (4.10.1911: 3) se hizo eco de tan terrible 
acontecimiento en un artículo en el que también destacaba la coherencia de sus convicciones democráticas, desvelando parte del testamento que un año antes, al poco de enviudar, redactó:

Yo, la abajo firmante, declaro (...) por ocasión de mi fallecimiento, deseo que me sea hecho entierro civil (...) Pido (...) que se dispensen del convencional luto (...) y expresamente les exijo que se abstengan de hacerlo usar a mi hija (...) Deseo, como ya dije, entierro civil y en todo demócrata (Ballesteros, 2001: 290).

A pesar de su breve existencia, se convirtió en una de las líderes más respetadas del movimiento feminista portugués. Había tenido la suerte de haber nacido en una familia de convicciones liberales. Su padre, Viriato Antònio Ângelo, periodista, debió ser un gran apoyo para su futura formación, y esta cuestión se puede poner en relación con el recibido por la doctora Cabete, por parte de su esposo, también liberal y defensor de los derechos de la mujer. También el padre de Ana de Castro era jurista, igual que el progenitor de Carmen de Burgos; como destaca García de León (2002), el nacimiento en familias liberales garantizaba más oportunidades para las mujeres.

Con Adelaide Cabete trabajó en el Hospital de Rilhafoles, y a partir de 1911, tras la proclamación de la Primera República, pasó a llamarse Hospital Miguel Bombarda en honor del médico psiquiatra y político republicano, importante miembro de la Masonería de Portugal, asesinado un año antes por uno de sus enfermos mentales.

Carolina Beatriz Ângelo, como su colega Adelaide Cabete, fue iniciada en la Masonería en 1907 en la Logia «Humanidade» adoptando el nombre simbólico de "Lígia». Un año después, en 1908, participó en el Primer Congreso Nacional del Libre Pensamiento. En 1920 Ana de Castro dirigiría, en su honor, la logia "Carolina Ângelo», donde fue iniciada también Carmen de Burgos en 1922, en prueba de reconocimiento mutuo y también de las que las precedieron.

Por su parte, la implicación con la causa feminista se materializaría formando parte de organizaciones como el Grupo Portugués de Estudios Feministas (1907); la Liga Republicana de Mulheres Portuguesas (1909), esta última animada por algunos de los dirigentes republicanos, como Antonio J. de Almeida o Bernardino Machado. Esta fue la primera organización feminista creada al abrigo de la República y también la primera en manifestar las primeras rupturas a causa de las posiciones encontradas en asuntos como el sufragio femenino o la libertad de conciencia. Por esta causa, la Liga se fractura y Carolina Ângelo y Ana de Castro, entre otras, fundan la Asociación de Propaganda Feminista (1912).

Ardiente pacifista, en 1907 había formado parte del Comité Português de La Paix et le Désarmement par les Femmes que tenía como objetivo resolver conflictos bélicos a través del diálogo. Pero su mayor triunfo fue, sin duda, el haber sido la primera mujer que ejerció el voto en Portugal tras la implantación de la Primera República que resultó 
tras la Revolución de octubre de 1910. El hecho histórico tuvo lugar durante las elecciones para la Asamblea Nacional Constituyente, el 28 de mayo de 1911. Le acompañaron Adelaide Cabete y Ana de Castro cuyo padre, el juez Joao Baptista de Castro, hizo posible que esto sucediera, defendiendo el recurso que la doctora había interpuesto al serle negado este derecho, alegando: «Onde a lei não distingue, não pode o julgador distinguir» (Silva, 1980). Fue una victoria pírrica porque el Código de 1913 establecería que sólo tenían derecho los ciudadanos portugueses «de sexo masculino» y mayores de 21 años. Al cabo de poco más de dos años Carolina moría, pero había sido la primera mujer del sur de Europa en ejercer este derecho ciudadano.

Carmen de Burgos Seguí (1867-1932), la futura «Colombine», nació en Rodalquilar (Almería) y murió en Madrid dejando atrás 65 años de una apasionante vida. Durante su infancia y adolescencia tuvo la fortuna de que José de Burgos, su padre (Cónsul de Portugal en Almería) le dio la mejor educación que se podía ofrecer en ese momento. Le abrió su biblioteca y le cedió sus periódicos, en línea con la influencia paterna determinante que rastreamos en casos como el de las escritoras Emilia Pardo Bazán (1851-1921) o Rosario de Acuña (1850-1923). Sobre todas las cosas, Carmen de Burgos fue una adelantada a su tiempo y por ello llegó a ser tildada despectivamente con apelativos como "La dama roja» o "La divorciadora», y su descrédito llegó al punto de ponerle su nombre a un prostíbulo de Almería (durante la dictadura franquista). Sin embargo, Carmen, fue mucho más. Se casó en 1883, con dieciséis años, y en contra del consejo paterno, con Arturo Álvarez Bustos, un bohemio pintor y periodista, bastante mayor que ella; un señorito calavera, adúltero y ocioso, de moral poco escrupulosa que fascinó a la inexperta Carmen. La relación matrimonial no fue positiva. Tuvieron varios hijos, de los cuales solo sobrevivió su hija María, que la acompañó siempre, y que nació en 1895. Poco después, Carmen se separa y en 1901 decide comenzar una nueva vida. Llegó a Madrid con su hija y un título de maestra que había obtenido estudiando por las noches y a escondidas de su esposo. Tenía 33 años y una plaza en un colegio de Guadalajara, pero lo que de verdad deseaba era vivir en Madrid, centro de la cultura. En 1906 falleció su esposo, quedó viuda e inició una larga relación amorosa y literaria con Ramón Gómez de la Serna. Carmen escribió bajo distintos pseudónimos: «Colombine», "Perico el de los palotes», "Gabriel Luna», "Honorine», «Raquel», "Marianela» o "Condesa Laureana» en muchas de sus variopintas publicaciones que van desde manuales de belleza hasta los temas más controvertidos ( $y$ comprometidos) como el feminismo, el adulterio, el divorcio, el espiritismo, la defensa del sefardismo, la corrupción política y la malversación de obras de arte.

A partir de 1902 colaboró con el periódico El Globo en el que escribía una columna titulada "Notas femeninas», donde analizaba asuntos como el sufragio. En 1903, Augusto Suárez de Figueroa fundó el Diario Universal y la contrató para llevar una columna diaria titulada «Lecturas para la mujer», bajo su seudónimo más conocido: 
«Colombine». Era la primera vez en España que una mujer era reconocida como periodista profesional. Hizo campaña para que se legalizara el divorcio, lo que le valió la admiración de Giner de los Ríos y Blasco Ibáñez, y los ataques por parte de la Iglesia y de los sectores conservadores que buscaron desacreditarla.

A su regreso de Francia, uno de los países que había visitado gracias a una beca para estudiar los sistemas educativos más modernos, creó una reunión semanal denominada "La tertulia modernista», a la que acudían escritores, periodistas, músicos, artistas plásticos, poetas y artistas extranjeros de paso por Madrid. Allí conoció a Ramón, entonces un desconocido estudiante de diecinueve años, veinte años menor que ella, que se convertirá en su pareja sentimental en una relación intermitente de 20 años. Cultivó una profunda amistad con Galdós, Blasco Ibáñez, Cansinos Assens, Juan Ramón Jiménez, Tomás Morales, Alonso Quesada, Julio Antonio, Julio Romero de Torres, Sorolla, etc. Desarrolló además una estrecha amistad con la escritora portuguesa Ana de Castro Osório. En 1905 fue admitida como socia del Ateneo de Madrid, donde compartió espacio con otras dos mujeres - Blanca de los Ríos y Emilia Pardo Bazán -, y en 1907 en la Asociación de la Prensa de Madrid, junto con la también escritora Consuelo Álvarez Pool «Violeta».

Trabajó, entre otras publicaciones, en El Universal, La Correspondencia de España, Heraldo de Madrid o ABC. Además de su intensa obra periodística, son destacables sus conferencias en el ámbito del movimiento feminista como La misión social de la mujer o La mujer en España.

Estuvo muy vinculada a Portugal desde su infancia, pues su padre era Cónsul honorario en Almería; también afirmaba que aprendió a leer ojeando el Jornal da Noticias (Núñez, 2005).Viajó y residió en aquel país durante temporadas más o menos largas. Durante sus viajes tomó contacto con las mujeres que tanto habían colaborado en la llegada del republicanismo como Ana de Castro, Adelaide Cabete o María Veleda, y conoció los trabajos de las primeras organizaciones feministas: A Liga Republicana de Mulheres Portuguesas (1909-1918), O Conselho Nacional (1914-1947), A Cruçada das Mulheres (1915-1919), liderada por su amiga Ana de Castro, y que le sirvió como ejemplo para fundar, hacia 1920, la Cruzada de Mujeres Españolas.

Como reconocimiento de su amor y compromiso con Portugal, fue condecorada con la Orden de Santiago y de la Espada, además de otras distinciones. Había dictado cursos de literatura en la Facultad de Letras de la Universidad de Lisboa, y escrito numerosos artículos sobre la nueva República y sobre sus personajes más notables, entre otros Teófilo Braga (1843-1924) o Bernardino Machado (1851-1944) para Heraldo de Madrid. En resumen, la «flor y nata» de la intelectualidad lusa del momento:- «Están en sus filas todos los grandes ingenios y todos los grandes políticos» (Utrera, 1988: 265). 
Entre su numerosa obra publicada destacamos algunas novelas con trasfondo autobiográfico como La malcasada (1923), Quiero vivir mi vida (1924, con un prólogo del Dr. Marañón sobre el sentido de los celos) o Los anticuarios (1926). Durante una de sus estancias en Portugal escribió novelas basadas en el espiritismo como: El retorno (basada en hechos reales), en 1922 o Los espirituados, en 1923. Tocó también temas tan controvertidos como la homosexualidad en Ellas y ellos ó ellos y ellas, en 1917. El registro de sus argumentos se extiende hasta manuales de belleza, cocina, urbanidad o la redacción de cartas. En 1931 se publicó su última novela larga: Puñal de claveles, con un argumento basado en el mismo episodio que García Lorca utilizó para Bodas de sangre (puesta en escena en 1933). Realizó numerosas traducciones de autores extranjeros, entre otros, Helen Keller, León Tolstoi, Paul Julius Moebius (La inferioridad mental de la mujer); Roberto Bracco (En el mundo de las mujeres: Conversaciones feministas), Max Nordau o Anatole France. Ejerció de corresponsal de guerra en 1909 en Marruecos, y una vez de vuelta a Madrid, publicó el artículo “iGuerra a la guerra!" en el que defendía a los pioneros de la objeción de conciencia.

Con la proclamación de la Segunda República en 1931, la nueva constitución reconoció el matrimonio civil, el divorcio y el voto femenino, cuestiones todas muy batalladas por Carmen de Burgos y por su amiga Ana de Castro que, en 1911, a través de la encuesta promovida por O Século (5 y 19 de abril de 1911) se manifiesta en su defensa. Fue este un año especialmente importante para ella: la Cruzada de Mujeres Españolas y la Liga Internacional de Mujeres Ibéricas e Hispanoamericanas la nombraron su presidenta y se afilió al Partido Republicano Radical Socialista. En noviembre de ese año fundó la logia "Amor". Murió el 8 de octubre de 1932; mientras participaba en una charla sobre educación sexual en el Círculo Radical Socialista. Tenía sesenta y cuatro años de edad y dejaba una huérfana, María. Tras la Guerra Civil, tuvo el dudoso honor de ser incluida en la «lista negra» de escritores elaborada por la dictadura franquista.

\section{2. Altavoces: pioneras del periodismo ibérico}

Nuestra segunda línea de reflexión transita por la labor profesional de quienes inauguran una nueva generación de periodistas.

En línea con el momento álgido del Periodismo literario (Cadalso, Larra, Bécquer) no fueron escasas, aunque sí borradas de la memoria colectiva, las escritoras pioneras que desde la mitad del XIX y principios del XX fundaron publicaciones, fueron propietarias 0 colaboraron en la génesis del periodismo contemporáneo. Independientemente de sus distintas filiaciones y sus objetivos dispares, comparten un proyecto común: la reivindicación y la educación de las mujeres. Aunque sus crónicas tratasen de moda, de labores o de tareas domésticas, el análisis sociológico del fenómeno supera las expectativas de género porque nos presenta la incorporación de estas mismas mujeres 
como profesionales, elevando su voz en el circuito de la opinión pública, tratando de normalizar su presencia, reclamando su autoridad, legitimándose como sujetos políticos.

Aunque han sido incorporadas a las historias nacionales de la comunicación y del periodismo contemporáneo como esporádicas contribuciones o como excepciones loables, su conocimiento contribuye a dibujar un panorama bastante más amplio y diverso del que, a priori, se estiman como referentes profesionales en el ámbito de la comunicación.

Así, estos indicios se han ido trazando a partir de aportaciones varias y preferentemente adscritas al ámbito de la Literatura: la obra fundamental de María del Carmen SimónPalmer (1991), la de Ossorio y Bernard (1903), Barradas (1998), Lopes (1981), los volúmenes monográficos de Arbor, revista del Consejo Superior de Investigaciones Científicas, uno dedicado a Carmen de Burgos (2020) y otro a las pioneras (2014). No es muy amplia la producción pero sí resulta sintomático que la exploración de una figura devenga en el desvelamiento de un grupo más que numeroso, a modo de "constelaciones" (Balló, 2018):

- Las pioneras: desde Beatriz de Cienfuegos (1714-1786), las románticas Cecilia Bölh de Faber y Ruiz de Larrea (1796-1877), Gertrudis Gómez de Avellaneda (1814-1873), Robustiana Armiño (1821-1890).

- Las isabelinas: Faustina Sáenz de Melgar (1834-1895), Ma Pilar Sinués de Marco (1835-1893) y Angela Grassi (1826-1883) analizadas por Sánchez LLama (2000); Joaquina García Balmaseda (1837-1893), Patrocinio de Biedma y La Moneda (18451927).

- Las heterodoxas Concepción Arenal (1820-1893), Emilia Pardo Bazán (1851-1921), Concepción Gimeno de Flaquer (1850-1919).

- Las librepensadoras Rosario de Acuña (1850-1923), Ángeles López de Ayala, Amalia Carvia, Belén Sárraga o Amalia Domingo Soler (Ramos, 2005).

Y así tantas otras hasta las 216 referenciadas por Díaz Nosty (2020) en un catálogo que no es solo cuantitativo sino cualitativo en la medida en que todas estas contribuciones coinciden con el proceso mismo de modernización del periodismo ibérico. Dicho esto, aprender una profesión o historiar la comunicación ignorando estos referentes resulta una osadía, una parcialidad, una injusticia, un borrado diríamos hoy, porque gran parte de lo que estas pioneras aportaron contribuyó indudablemente a profesionalizar un oficio, a fijar unas temáticas, a priorizar unos enfoques informativos y a informar sobre las mujeres como sujetos plenos, incluso innovando en las maneras más vanguardistas de relatar la realidad desde la inmersión, tal y como hizo Magda Donato respecto al "periodismo gonzo"(Bernard, 2008) 
Lo mismo podemos decir de nuestras colegas portuguesas con las que compartimos unos devenires históricos comunes y también el mismo manto de silencio sobre la existencia de las profesionales. Son los relatos de las coetáneas, sistematizados por Ángeles Ezama (2020 y 2014), las que nos informan de esas genealogías lusas.

Pardo Bazán (1897) cita a Guiomar Torreçao (Germano, 2010), editora del Almanach das Senhoras (1872-1898). Concepción Gimeno (1900) a Enriqueta Pereira da Sousa, editora de Hymnos e Flores.

En una conferencia para la Unión Iberoamericana de Madrid (1905), Carmen de Burgos cita a varias periodistas portuguesas: María Amalia Vaz de Carvalho (1847-1921), colaboradora del Jornal do Comércio, Repórter, Artes e Letras, Diário de Notícias, Novidades, Ocidente y Comércio do Porto, donde practica, especialmente, la crítica literaria, y a Claudia Campos, corresponsales ambas en Brasil. Alice Pestana (1860-1929) en el Diario de Lisboa, Alice Moderno (1867-1946) fundadora de A Folha en las Islas Azores, Maria Olga Moraes Sarmento (1881-1948) directora de la revista Sociedade Futura (creada por Ana de Castro en 1902), María Veleda (1871-1955) colaboradora de la Revista Branca creada por Pestana, Virginia Quaresma (1882-1973), considerada como la primera periodista profesional, redactora en Alma Feminina (1907-1908), O Século y A Capital y luego en A Época en Rio de Janeiro desde 1912 a 1917. Sobre el protagonismo de la primera profesional del periodismo no faltan controversias, pues también hay referencias en este mismo sentido que señalan a Antonia Gertrudes Pusich (1805-1883) directora de «A » assemblea litteraria : jornal de instrucção / D. A. G. Pusich. - Lisboa : Typ. de G.M. Martins, [1849?]-1851, como la primera. En cualquier caso, lo que no tiene objeción alguna es el abundante plantel de periodistas.

Destacamos, sin embargo, que nuestro itinerario segundo se sustenta pues en la exploración de la dimensión periodística, además de la literaria y la política, de Carmen de Burgos y en su vinculación con la activista Ana de Castro, en la medida en que no solo son coetáneas sino que su devenir entre la acción política, la creación de organizaciones y la práctica de un periodismo comprometido son claramente adyacentes. Que ambas tuvieran mutuo interés por lo que ocurría a un lado y al otro de la península no es tampoco excepcional, pues era una práctica común entre las élites políticas republicanas. Como afirma Concepción Núñez, la posibilidad es más interesante pues no se trata de espejos, de una observación mutua o de trayectorias históricas similares, sino de puentes basados en el interés común y en el reconocimiento (Núñez Rey, 2014). Carmen de Burgos y Ana de Castro se conocieron en 1915 cuando ambas ya tenían tras de sí una importante trayectoria profesional y una presencia consolidada entre las élites intelectuales y políticas de sus respectivos países. Ambas, en plena madurez profesional y vital, tenían un acumulado bagaje en la vindicación de los derechos de las mujeres que compartían con otras militancias: la pacifista, la abolicionista, la republicana, un afán pedagógico indudable y la vinculación con la masonería. 
Ana de Castro Osório (1872-1935), publicó Às Mulheres Portuguesas (1905), considerado el primer manifiesto feminista portugués. Fundó el Grupo Português de Estudos Feministas (1907), la Liga Republicana das Mulheres Portuguesas (1909) y la organización sufragista Associação de Propaganda Feminista (1912). Su activismo político transitó paralelo a su trabajo propagandístico que difundió a través de las publicaciones que dirigió, como Sociedade Futura (1902), O Jornal dos Pequeninos (1907-1908), A Mulher e a Criança (1909-1910), A Semeadora (1915-1918), y en los medios en los que colaboró como el diario O Radical (1910-1911) y en la editorial Lusitânia Editora Limitada que fundó en 1914.

Contrajo matrimonio en 1898 con el periodista y poeta Francisco Paulino Gomes de Oliveira, que fue nombrado en 1911 cónsul de Portugal en São Paulo; de su estancia en Brasil, Ana de Castro trajo reforzadas sus ideas sobre la alianza de los pueblos, su crítica al dominio sobre Brasil y su apuesta por la necesidad de una integración geopolítica, económica y una unión etnocultural, ideas que ya había teorizado en $A$ Grande Aliança: A Minha Propaganda no Brasil (1890) (cit. Castro, 2011). Trasladó su ideología también al iberismo en una utopía de enorme importancia en este periodo del siglo XX desarrollando una postura integradora que explicita en una serie de artículos en la Revista de la Raza. Publicación de Estudios Internacionales, órgano de la Alianza Hispano-Israelita, una publicación pro-sefardita que se convirtió a partir de 1924 en el portavoz de la Liga Internacional de Mujeres Ibéricas e Hispanoamericanas (Ezama Gil, 2013).

A su regreso a Lisboa, en el contexto de la Primera Guerra Mundial, fundó la Comissão de Mulheres Pela Pátria, a partir de la que se constituyó en la Cruzada das Mulheres Portuguesas (1916) organización de tipo humanitario para la población civil, a la vez que ejercía como Subinspectora de Trabajo, actividad que vincula a su compromiso social con las clases trabajadoras y, especialmente con las mujeres. En paralelo pero con un sentido integral de regeneración social y de compromiso con los colectivos más desfavorecidos, la faceta complementaria de Ana de Castro como escritora de literatura infantil y como editora (Livraria Editora Para Crianças, Setúbal, 1897) no es accesoria sino estratégica y también coincidente con el afán pedagógico de Carmen de Burgos. Asegurar la educación de los niños y las niñas es también un proyecto esencialmente político, y hacerlo a partir de pedagogías modernas en escuelas laicas y mixtas, y docentes con formación basada en psicología infantil y materiales adecuados a estos nuevos métodos; entre otros los que ella misma edita, y realizados a partir de la tradición oral o de la traducción de relatos del folclore europeo en un ejercicio consciente de recabar y valorar el patrimonio popular al margen del pensamiento conservador y del interés nacionalista como conjunto de saberes populares (Castro Gomes, 2011). 
Sus frentes son diversos pero complementarios, su labor propagandística y la trasmisión a la opinión pública de su ideario. El valor del trabajo y del conocimiento son axiales, y la necesidad de que las mujeres accedan a ambas facetas es su prioridad. Todos los medios de los que dispone, desde la acción política a la acción comunicativa son paralelos porque apuntan a objetivos diferenciados. Con semejante trayectoria, tal vez sea la más desdibujada la periodística, pero no la menos importante. En cualificada opinión de Isabel Lousada (2012: 66, cit por Ezama 2013: 103) el perfil de Ana de Castro, también como periodista, es indudable: "A finalizar, notemos Ana de Castro Osório, na qualidade de jornalista pioneira, e os quadros da condição social das mulheres por si feitos a serem amplamente divulgados na imprensa. Dotada de uma escrita simultaneamente arguta e bela, Ana de Castro Osório abriu camino às jovens que lhe sucederam, que como ela se iniciaram nas lides jornalísticas e vocacionadas para tal, a elegeram como profissão". La misma Lousada afirma que en el caso portugués, la prensa fue un recurso más estratégico y no tanto un órgano de expresión de las asociaciones (Lousada 2012: 61 cit. por Ezama 2014:3) pero también eso sea un signo de la modernidad de un periodismo que ya no solo es portavoz. De hecho, estas periodistas se debaten entre modelos informativos en transición: el francés del XIX fundamentado en la crónica, y el modelo anglosajón del XX interesado por géneros vibrantes, entrevistas y reportajes. Ellas mismas personifican y protagonizan esa transición mediante sus crónicas de viajes, entrevistas, reportajes.

El encuentro de 1915 entre Carmen de Burgos y Ana de Castro viene precedido de un afectuoso acompañamiento. La llegada a Lisboa se plasma en una entrevista conducida por Ana de Castro y publicada en la portada de A Capital (23.8.1915) con el titular "Colombine está en Lisboa" y una elogiosa semblanza. En el Hotel Continental se encuentran y se descubren en numerosas afinidades y en mutua confianza. Núñez (2014) no duda que fue Ana de Castro quien le abrió las puertas a las más altas instituciones y a las más relevantes personalidades, visitando redacciones de periódicos, entrevistando a personajes ilustres. Desde el viaje de vuelta y antes incluso de llegar a Madrid, Carmen de Burgos avanzaba sus reflexiones y comenzaba a publicar en Heraldo de Madrid sus artículos "De Portugal” donde entrevista, por orden, a Magalhaes Lima, al presidente de la República en funciones Teófilo Braga, a Bernardino Machado, a la periodista Virginia Quaresma, a la primera abogada del país Regina de Quintanilha y concluye con Ana de Castro (Heraldo de Madrid 30.10.1915) de quien trascribe: (...) yo estoy enamorada de la lucha por la libertad, por los derechos de nuestro sexo, por todas las grandes reformas sociales(...).

También Carmen de Burgos se interesa particularmente por la trayectoria profesional de Virginia Quaresma (1882-1973). En la referida entrevista (30.9.1915), Carmen de Burgos alaba la vocación de reportera de Quaresma y afirma: “Los grandes triunfos del periodismo moderno no son triunfos de literatos ni de cronistas; son triunfos de reporter" (Ezama, 2014). Quaresma fue pionera en otros muchos aspectos y rompedora, 
como Colombine, de la estricta moral conservadora que rechazaba no solo su orientación sexual sino su propia existencia. De padre militar y madre descendiente de esclavos africanos, tuvo como compañera a la también periodista María Cunho Zorro (1862-1917). Ambas marcharon a Brasil donde trabajaron como periodistas entre 1912 y 1917, cubriendo, particularmente, noticias de sucesos donde mostró un especial tratamiento de la violencia contra las mujeres (Seixas, 2004). Quaresma trabajó en Alma Feminina, en el diario O Século, en A Capital y también en la Agência Americana de Noticias (AAN) donde desarrolló numerosos reportajes, entendido como el género más completo y más vibrante, el que permitía abordajes más amplios y la incorporación de otros sujetos informativos como las mujeres, la infancia, las clases populares.

\section{Conclusiones}

Más que conclusiones, estas líneas son posibilidades de reconstrucción. Los perfiles revisados muestran los rasgos propios de la genealogía feminista: la centralidad del sujeto mujeres, la recuperación histórica de sus saberes y el carácter personal y político de la indagación sobre estas mujeres. Sus vidas y sus trayectorias son similares a las de sus coetáneas, entroncan con otras redes y con otros itinerarios. Como fueron incansables viajeras, ampliaron sus contactos y establecieron unos vínculos que les facilitaron el encuentro con otras activistas y con sus organizaciones en toda Europa y en América. Indudablemente estas experiencias se trasladaron a sus reportajes informativos, a sus relatos de viajes, a sus conferencias. Por eso, esta indagación no deja de ser una vía, un camino a recorrer donde ya se han descrito ciertos hitos.

Nuestras trayectorias en la formación superior en periodismo en España y Portugal resultan paralelas (Marinho y Sánchez García, 2020) y tienen su auge y sentido pleno con la recuperación de la democracia con estudios de Comunicación en la Universidade Nova de Lisboa (1979) y de Periodismo en Coimbra (1991), con Ciencias de la Información en la UCM y en la UAB en 1971. A partir de aquí, fructificaron un importante número de centros, de títulos, de especializaciones pero con referentes profesionales sesgados. Las pioneras, las antecesoras, las que hemos mencionado, las que desempeñaron luego su trabajo en la radio, en la televisión, las que anunciaron e informaron sobre los cambios sociales, sobre los procesos democráticos ${ }^{1}$ (Fonseca, 2014) precisan del reconocimiento general. Quienes ejercen el periodismo en el siglo

\footnotetext{
${ }^{1}$ La locutora Clarisse Guerra fue la que leyó el comunicado emitido por la MFA en la radio en la que trabajaba como locutora, la Radio Clube Portugues. Véanse otras protagonistas en el reportaje "Y el grito de la revolución fue de las mujeres" Píkara Magazine 25.04.2014 https://www.pikaramagazine.com/2014/04/y-el-grito-de-la-revolucion-fue-de-las-mujeres/ Cfr. Fonseca, 2014.
} 
XXI demandan referentes, modelos, sentir que están en un territorio que no les es ajeno, que también les corresponde porque antes otras abrieron el camino, demostraron su profesionalidad e informaron sobre las cuestiones importantes, las que incluían a toda la ciudadanía, las que contaban lo que ocurría, lo que deseaban y lo que exigían.

\section{Referencias bibliográficas}

ÁLVAREZ, F. El método genealógico: ejemplificación a partir del análisis sociológico de la institución manicomial. En GORDO, Á. J. y SERRANO, A. (Eds.). Estrategias y prácticas cualitativas de investigación social, Madrid, Parsons Educación.

BALLESTEROS, R. M. (2017). «El feminismo "ben comportado" de Ana de Castro Osório», en LEÓN, M., ORTEGA, V. J., BLANCO, S. (eds.), Mujeres Iberoamericanas y Derechos Humanos. Experiencias feministas, acción política y exilios, Málaga, Ediciones Universitarias Athenaica, 109-132.

- (2012). "Carmen de Burgos Seguí», en SÁNCHEZ, I. (coord.), Educación, Ciencia y Cultura en España: Auge y colapso (1907-1940), Almud, Ediciones de Castilla-La Mancha, 125-127.

- (2005). "Las distracciones misteriosas: Colombine y la masonería portuguesa», en Aposta digital. Revista de Ciencias Sociales, n 15, febrero, 1-21.

- (2004). «Portugal y las organizaciones de mujeres: La prensa feminista», en BALLESTEROS, R. M., VERA, M. T. (coords.), Mujeres y Medios de Comunicación: Imágenes, Mensajes y Discursos, Málaga, Universidad, Atenea, 21-58.

- (2002a). «Cartas a una amiga portuguesa (Carmen de Burgos a Ana de Castro Osório)»: La Mujer (II). Actas III Congreso de Andalucía. Córdoba, Publicaciones Obra Social Cultural Cajasur, 21-39.

- (2002b). «Portugal y los Congresos Feministas y de Educación (1924-1928)», en Docencia e Investigación. Revista de la Escuela Universitaria de Magisterio de Toledo, año XXVII (enero-diciembre), 20 época, no 12, 7-39.

- (2002c). «Algunas consideraciones en torno a la prostitución. El Primer Congreso Abolicionista Portugués (1926)», en LÓPEZ, M. T., JIMÉNEZ, M. J., GIL, E. (eds.), Violencia y Género (T. I), AEHM, Actas Congreso Internacional. Málaga, Diputación Provincial de Málaga, 229-241.

- (2000a). María Veleda, Madrid, Ediciones del Orto. 
- (2000b). «La Masonería: La busca de un espacio femenino autónomo. El caso de las logias femeninas independientes en Portugal», en CERRADA, A. I., SEGURA, C. (eds.), Las mujeres y el poder: Representaciones y prácticas de vida, Madrid, ALMUDAYNA-AEIHM, 225-243.

- (1999a). El movimiento feminista portugués: Del despertar republicano a la exclusión salazarista (1909-1947), Málaga, Universidad de Málaga, Col. Atenea. X Premio de Investigación Victoria Kent.

- (1999b). «La Paz en el discurso feminista portugués», en Mujeres, regulación de conflictos sociales y cultura de la paz, Valencia, Universidad de Valencia, 201-211.

BALLÓ, T. (2018). Las sinsombrero 2. Ocultas e impecables, Madrid, Espasa.

BARRADAS, A. (1998). Dicionário Incompleto de Mulheres Rebeldes, Lisboa, Edições Antígona.

BERNARD, M.; CHIERICHETTI;, L. GONZÁLEZ DE SANDE, M.; ROTA, I. (eds) (2008).Papel de mujeres/Mujeres de papel. Periodismo y comunicación del siglo XIX a nuestros días, Bergamo, Bergamo University Press.

BOURDIEU, P. (2000). La fuerza del derecho. Elementos para una sociología del campo jurídico. En Poder, derecho y clases sociales, Bilbao, Desclée de Brower, 165-223.

CIRIZA, A. (Septiembre, 2012). Genealogías feministas: sobre mujeres, revoluciones e

ilustración: una mirada desde el sur. Revista Estudos Feministas, 20(3), 613-633.

COUTINHO, C. P. (2014). Metodologia de Investigação em Ciências Sociais e Humanas (Research Methods in Social Sciences and Humanities), Coimbra, Almedina.

CASTRO GOMES, Angela de (2011). “A Grande Aliança de Ana de Castro Osório: un projeto politico-pedagógico fracassado" en Estudos do Século XX, Imprensa da Universidade de Coimbra, 11, 281-299.

DA CRUZ, Eduardo; COUTINHO ORNELLAS, Barbara (2018). A participaçao feminina no periódico Brasil-Portugal (1899-1914). Rev. Interd. em Cult. e Soc. (RICS). São Luis, v. 4, n. especial dossiê temático, 29-47

DA SILVA, M. (1983). Feminismo em Portugal na voz de mulheres escritoras do início do século XX. Análise Social, 19(77/79), terceira série, 875-907. Retrieved June 4, 2021, from http://www.jstor.org/stable/41010433

DÍAZ NOSTY, B. (2020). Voces de mujeres, periodistas españolas del siglo XX nacidas antes del final de la guerra civil, Sevilla, Renacimiento. 
ESTEVES, J. (2005). "Ana de Castro Osório», Dicionário no Feminino (séculos XIX-XX), Lisboa, Livros Horizonte. pp. 91-99.

- (1998). As origens do sufragismo portugués, Lisboa, Bizâncio

- (1992). A Liga Republicana das Mulheres Portuguesas-uma organização política e feminista (1909-1919), Lisboa, ONG da CIDM.

- y RUY, J. (2016). Carolina Beatriz Ângelo. Pioneira na cirurgia e no voto, Ancora Editor.

EZAMA GIL, María de los Ángeles (2010). La "Unión ibérica" de escritoras entre los siglos XIX y XX. Estudios portugueses: revista de filología portuguesa, 10, 57-78

EZAMA GIL, Ángeles (2013). “Ana de Castro Osório, una mujer que traspasó fronteras: sobre unos textos olvidados en la española Revista de la Raza" Revista de Escritoras Ibéricas, 1, 2013, 101-128 https://doi.org/10.5944/rei.vol.1.2013.1152)

EZAMA GIL, Ángeles (2014). Las periodistas españolas pintadas por sí mismas. Arbor: Ciencia, pensamiento y cultura, ISSN 0210-1963, № 767 (mayo-junio 2014), 2014 (Ejemplar dedicado a: Mujer y periodismo en el siglo XIX. Las pioneras)

FARIÑA BUSTO, M. J. (2019). "El beso deseado de tu boca". Nombres y voces para una ginealogía lesbiana (España y Portugal, primeras décadas del siglo veinte). Investigaciones Feministas, 10(1), 79-96. https://doi.org/10.5209/infe.61064

FLECHA, C. (2019). "Barreras ante las pioneras universitarias: una mirada transnacional», en CIAN Revista de historia de las universidades, Vol. 22, no. 1, pp. 19-59.

- (1996). Las primeras universitarias en España: 1872-1910, Madrid, Narcea.

FONSECA, A.S. (2014). Capitãs da Abril, Lisboa, A esfera dos libros.

GARCÍA DE LEÓN, M. (2002). Herederas y Heridas. Sobre las élites profesionales femeninas, Madrid: Cátedra; Universitat de València; Instituto de la Mujer.

GERMANO DE OLIVEIRA ROMARIZ, Andrea (2011). O Almanaque de Lembranças LusoBrasileiro: um ensaio para um Projecto maior? Universidade de Lisboa, Mestrao em Estudos Cultura Românicos Portuguesa https://repositorio.ul.pt/handle/10451/5145

GUIMARĀES, E. (1986). Mulheres Portuguesas: ontem e hoje, Lisboa, Comissão da Condição Feminina, pp. 12-13.

LOPES, A. (1981). Dicionário de mulheres célebres, Porto, Lello \& Irmao. 
LOUSADA, Isabel (2010). Impresa: amplificador da voz feminina, Cámara Municipal de Lisboa

LOUSADA, Isabel (2012). "Elas de progresso social e científico: contributo para a História das Mulheres Cientistas em Portugal", in Women, Science and Globalisation. What's up?. Lisboa: Amonet, 57-85.

LOUSADA, Isabel (2014). Feminismo en la voz de una periodista feminista. Virginia Quaresma. AEHIM http://hdl.handle.net/10362/13925

LOUSADA, I. (2017). Perfil de Uma Pioneira: Adelaide Cabete (1867-1935), Editora Fonte da Palavra, Associação Cedro (Março).

MARINHO, Sandra y SANCHEZ-GARCIA, Pilar (2020). Historia de la enseñanza del Periodismo en España y Portugal: una línea de tiempo con paralelismos y contrastes. Cuad.inf. [online], 47, 138-161.

MARQUES, F. (s.a.). A Maçonaria Feminina, Lisboa, Editorial Vega.

MOLINA, C. A. (1990). Sobre el iberismo y otros escritos de literatura portuguesa, Madrid, Akal.

NÚÑEZ REY, C. (2014). Un puente entre España y Portugal: Carmen de Burgos y su amistad con Ana de Castro Osório. Arbor, 190(766), a115. https://doi.org/10.3989/arbor.2014.766n2007

OSSORIO Y BERNARD, Manuel (1903). Ensayo de un catálogo de periodistas españoles del siglo XIX, Madrid, Imprenta y litografía de J. Palacios.

PÉREZ ISASI, S. y RODRIGUES, C. S. (2021). «Escritoras e intelectuales mujeres en las redes de intercambio cultural ibérico (1870-1930): tareas pendientes», en ROMERO MORALES, Y., CERULLO, L. y LAROUSSI, S. (eds). Senderos que se bifurcan. Alteridad y género en el mundo literario hispánico, Madrid, Silex

RAMOS, M. D. (2002). «Federalismo, laicismo, obrerismo, feminismo: cuatro claves para interpretar la biografía de Belén Sárraga», en RAMOS, D., VERA, T. (coords.), Discursos, realidades, utopías: la construcción del sujeto femenino en los siglos XIXXX, Barcelona, Anthropos, pp. 125-164.

RAMOS, M. D (2005). La República de las librepensadoras (1890-1914): Laicismo, emancipismo, anticlericalismo. Ayer, (60), 45-74.

RESTREPO, Alejandra (2016). "La genealogía como método de investigación feminista", XI congreso iberoamericano ciencia, tecnología y género 26-28 julio 2016 https://congresoctg.ucr.ac.cr/memoria/descargar.php?id=30. 
RODRÍGUEZ MAGDA, R. M. (1997). Del olvido a la ficción. Hacia una genealogía de las mujeres. En Rodríguez, R. M. (Ed.). Mujeres en la historia del pensamiento, Barcelona, Anthropos.

RODRIGUEZ MAGDA, R. M. (2004). Foucault y la genealogía de los sexos, Barcelona, Anthropos.

SÁNCHEZ LLAMA, I. (2000). Galería de escritoras isabelinas. La prensa periódica entre 1833 y 1895, Madrid, Cátedra.

DO SAMEIRO BARROSO, M. (2017). Carolina Beatriz Ângelo: a pratica da Medicina e a luta pelos direitos das mulheres. Medicina Na Beira Interior- Da Pré-História Ao Século XXI, XXXI(Novembro), 75-80.

SEIXAS, Maria Augusta (2004). Virgínia Quaresma (1882-1973). A primeira jornalista portuguesa. Tesis de Mestrado (Tercer Ciclo) en Comunicación y Periodismo. Coimbra, Faculdade de Letras, Universidade de Coimbra.

SILVA, M.R. (1980). "Carolina Beatriz Ângelo», en Mulheres, n.ㅇ 27 (Julho), p. 3.

SILVA, A. e outros (1997). Adelaide Cabete. Alma de Mulher, Lisboa, Câmara Municipal.

SIMÓN PALMER, María del Carmen (1991). Escritoras españolas del siglo XIX. Manual bio-bibliográfico, Madrid, Castalia.

TAVARES, M. R. (1982). Feminismo na voz de mulheres escritoras do início do século XX, Lisboa, Comissão da Condição Feminina.

UNAMUNO, Miguel de (1972). En torno al casticismo, Madrid, Espasa-Calpe.

UTRERA, F. (1998). Memorias de Colombine, la primera periodista, Hijos de Muley Rubio, S.L.

VENTURA, Isabel (2012). As Primeiras Mulheres Repórteres: Portugal nos anos 60 e 70, Lisboa, Tinta da China. 